\title{
Los museos: ¿Espacios para incentivar conocimientos y disertaciones sobre el pasado?
}

\author{
Museums: spaces to stimulate knowledge \\ and dissertations about the past?
}

\author{
Saúl Fernando Uribe Taborda ${ }^{1}$ \\ suribe@ups.edu.ec
}

\begin{abstract}
Resumen
El presente artículo reflexiona el rol del museo como institución que salvaguarda y conserva los vestigios del pasado, cuya función se configura como espacio estructurador, condicionante y eje institucional de las miradas hacia la memoria social y colectiva de los pueblos latinoamericanos. En este trabajo argumento cómo el museo constituye un espacio que contribuye a la reproducción y legitimación de ideas e ideologías enraizadas en el proyecto de modernidad/colonialidad, y cómo se establecen visiones del pasado que excluyen las historias y experiencias de los "otros".
\end{abstract}

\section{Palabras clave}

Museo, proyecto de modernidad/colonialidad, subalternidad, América Latina.

\begin{abstract}
This article reflects the role of the museum as an institution that safeguards and preserves vestiges of the past, whose function is set to structuring space constraint and institutional axis looks towards social and collective memory of Latin American peoples. In this paper we argument how the museum is a space that contributes to the reproduction and legitimation of ideas and ideologies rooted in the project of modernity/coloniality, and how visions of the past that exclude the stories and experiences of the "others" are set.
\end{abstract}

\section{Keywords}

Museum, project of modernity/coloniality, subalternity, Latin America.

Forma sugerida de citar: Uribe Taborda, Saúl Fernando (2016). Los museos ¿Espacios para incentivar conocimientos y disertaciones sobre el pasado? Universitas, $X I V(25)$, pp. 17-30.

1 Doctorante en Ciencias Sociales de la Universidad Pontificia Bolivariana Sede Medellín. Maestro en Estudios Socioambientales de la Facultad Latinoamericana de Ciencias Sociales FLACSO-Ecuador. Antropólogo de la Universidad de Antioquia. Docente de la Universidad Politécnica Salesiana del Ecuador. Grupo de Investigación Estado y Desarrollo de la Universidad Politécnica Salesiana (GIEMST). ID. orcid.org/0000-0001-7712-8334 


\section{I}

Las nociones históricas que fundamentan la creación de los museos tienen su origen, principalmente, en dos momentos de la historia europea: por un lado, la existencia del coleccionismo, y por el otro el fenómeno de la Ilustración. En un primer momento el coleccionismo en Europa tuvo su auge con las monarquías absolutas, y paralelo a ellas, con el creciente interés de agentes privados o estatales por poseer los objetos más valiosos, provenientes del prolongado proceso de saqueo, emprendido a inicios del siglo $\mathrm{X}$ al Imperio Babilónico en el Antiguo Oriente (Hernández, 1992).

El coleccionismo, al ser una tradición muy propia del carácter europeo, halló partidarios al otro lado del océano, originando la creación de los primeros museos americanos. Estos museos albergaron un sinnúmero de objetos que provenían de colecciones privadas, y cuyos orígenes eran tan diversos y singulares como los pueblos a los cuales pertenecían, los cuales fueron saqueados algunos siglos atrás.

Las iniciativas de los coleccionistas privados consolidan la idea y el futuro de las instituciones que posteriormente se conocerían como museos. El ideario de los coleccionistas, unido al acelerado crecimiento económico de la naciente potencia americana, promovió de forma generalizada la creación de estos espacios como medio para contrarrestar el vacío cultural (Hernández, 1992).

El segundo momento que influyó en la creación de los museos es consecuencia inmediata de la Ilustración. El movimiento Ilustrado europeo tuvo como meta edificante ceñir al mundo a la elucubración de la razón. Sus procesos culturales e intelectuales influenciarían enérgicamente en la concepción sobre la cultura y sus pensadores ${ }^{2}$, quienes se plantearon extirpar la ignorancia a partir de la imposición de la razón para suprimir la superstición y la tiranía, creando así los preceptos que condensaban la idea de crear una humanidad mejor (Im Hof, 1993).

Los pensamientos de la Ilustración, originados a finales del siglo XVII culminaron con la Revolución Francesa en 1799, y seis años antes de su finalización, en 1793, abre sus puertas el museo de Louvre como testimonio de este proceso, el cual serviría a la postre como modelo para crear los grandes museos nacionales europeos. Sin embargo, antes de ser construido e in-

2 D’Alembert, Descartes, Locke, Bacon, Bayle, Galileo, Grotius, Hobbes, Leibniz, Newton, Spinoza entre otros. 
augurado el museo de Louvre, en 1683 había abierto las puertas el museo Ashmolean Museum, cuyo custodio fue la Universidad de Oxford.

La dirección del Ashmolean Museum estaba a cargo del naturalista Robert Plot, y contenía un sinnúmero de colecciones privadas de diversa índole; en sus salas se podían encontrar grandes colecciones de historia natural, arqueología y numismática, y pinturas de diversas épocas y estilos. Su objetivo más allá de conservar y educar, Indica más bien una obsesión por solidificar las ideas del pensamiento ilustrado europeo (Hernández, 1992).

Los objetivos de los museos fueron tan extensos como sus colecciones, algunos de ellos versaban por la conservación y preservación de los objetos más suntuosos y exclusivos de las colecciones privadas con las que fueron creados; otros, como el museo Ashmolean Museum, habían sido propuestos para la investigación científica. Si bien sus objetivos eran diversos, todos ellos poseían una particularidad: la exclusividad de sus visitantes y el carácter científico del lenguaje que acompañaban a las colecciones albergadas, restringiendo el acceso a grandes sectores de la población europea (Hernández, 1992).

Por ejemplo, el acceso al Museo del Prado sólo era posible el día miércoles y estaba sujeto a previa autorización o recomendación escrita de una figura de la Corte, esto ocurría en 1820, al año siguiente de inaugurarse el Museo (Pérez, 1977). El Museo lograba una suerte de sentimiento sacro que fundó el destino exclusivo, excluyente y burgués de los museos. Los museos rápidamente se convirtieron en los espacios para el deleite aristocrático, y sus ideales de la razón Ilustrada legítimo la exclusión y la racialización de las sociedades, profundizando aún más las diferencias de clase.

Los museos adquirían su legitimidad social e institucionalizaban algunas prácticas académicas como la etnografía, la botánica y las artes, pero al mismo tiempo justificaban las razones del colonialismo y los antivalores adjudicados a las expresiones de otras culturas. Por ejemplo, en el caso de la etnografía, Césaire (2006) interpela a Roger Caillois cuando argumenta que "sólo hay etnografía blanca", pretexto por el cual Occidente adquirió el derecho absoluto, exclusivo e imperial sobre las prácticas etnográficas de todo el género humano, y no los otros los que hacían la etnografía de Occidente. Ante este tipo de reduccionismos culturales y hegemonías académicas surgieron poderosas voces que responderían enérgicamente a los planteamientos, por ejemplo, de Roger Caillois. Césaire argumentaría que: 
Y ni por un minuto se le pasa por la cabeza al señor Caillois que habría valido más, mirándolo bien, no haber tenido necesidad de abrir los museos de los cuales se jacta; que Europa habría hecho mejor tolerando a su lado a las civilizaciones extraeuropeas, realmente vitales, dinámicas y prósperas, enteras y no mutiladas; que habría valido más dejarlas desarrollarse y realizarse, que damos para admirar, debidamente etiquetados, sus miembros dispersos, sus miembros muertos; que, a fin de cuentas, el museo no es nada por sí mismo; que no quiere decir nada, que no puede decir nada, allí donde la plácida satisfacción de sí mismo pudre los ojos, allí donde el oculto desprecio de los demás deseca los corazones, allí donde el racismo, confesado o no, acaba con la simpatía; que no quiere decir nada si no está destinado a alimentar las delicias del amor propio; que, después de todo, el honesto contemporáneo de San Luis, que combatía al islam pero lo respetaba, tenía mayores posibilidades de conocerlo que nuestros contemporáneos, que aún barnizados de literatura etnográfica lo desprecian (Césaire, 2006, p. 9)

Los derechos y la exclusividad que se otorgó Occidente para construir el pasado de los "otros", trazó el destino de las historias, las culturas y las sociedades en todas las latitudes a las que llegaron sus prácticas de segregación y domesticación. Hordas de saqueadores se esparcieron por poblados, pueblos y grandes ciudades sometiendo todo aquello que fuese diferente a ellos, su premisa no fue otra más que colonizar, saquear, reducir y civilizar a todos los conglomerados humanos que deambulaban naturalmente y con un tipo muy bien definido de cultura. Su saqueo fue tan prolífico que pronto se llenarían grandes colecciones privadas y públicas de diversos objetos que pasaron a ser parte de los grandes museos de Occidente, "cuna de la civilización de la tierra".

\section{II}

La razón, valor rector de la Ilustración europea, constituye un punto de inflexión que proporciona insumos para realizar una reflexión sobre el museo en América Latina, al ubicar la discusión en el plano de la razón ilustrada de Europa. En otras palabras, las ideas de la Europa moderna se convirtieron en la expansión colonial que buscó la "imposición de una política imperial del lenguaje" (Castro-Gómez, 2010, p. 13). Esta política del lenguaje se tradujo en América Latina como un proceso de exclusión, racialización e imposición de una cultura que hace de la Ilustración un gesto para la 
simplificación o la reducción de las manifestaciones sociales a expresiones monolíticas desvalorizadas y expuestas en salas de museos.

El pasado y las construcciones sociales sobre los objetos de gran valor cultural en América Latina quedaron limitadas a simples cosificaciones de las normas coloniales impuestas por la razón ilustrada, cuando eliminó las historias "de los colonizados", y oculto la posibilidad de ser escuchadas, pensadas y posicionadas como proyectos que rompieran con el colonialismo, singular característica de los museos europeos. Castro-Gómez argumenta que Kant en 1774 respondía a la pregunta: " ¿Was ist Aufklärung? ${ }^{3} \mathrm{La}$ Ilustración es "la salida del hombre de la minoría de edad", entendida ésta "como la incapacidad de servirse del propio entendimiento sin la dirección de otro" (Castro-Gómez, 2010, p. 21).

La razón ilustrada en América Latina no sólo fue una estrategia que instauró un ejercicio político violento del lenguaje, detrás de ella se fijaron las bases para la formación del Estado nación, y con éste la idea de una identidad nacional que terminó por homogenizar a las ya reducidas poblaciones Latinoamericanas. La Revolución Francesa, empero, marcó el ocaso de la Ilustración europea, y abrió el camino para los nuevos proyectos políticos en el mundo, en los cuales la política imperial del lenguaje (Castro-Gómez, 2010) posibilitó la expansión colonialista de Europa, permitiendo que los pensamientos políticos surgidos en el seno de la Revolución se expandieran rápidamente por América Latina.

Bajo los efectos efervescentes de las ideologías nacionalistas del siglo $\mathrm{XX}$, los partidos políticos en América Latina asumieron las banderas de la lucha anticolonialista. Su consigna fue expulsar a Europa y Norte América, allanando el camino para el surgimiento de nuevas ideas, que pronto lograron materializarse en estrategias nacionalistas, enfocadas al desarrollo de los territorios latinoamericanos; es así que el enaltecimiento de la grandeza del pasado prehispánico pretendió afianzar la existencia de una identidad nacional, cuya más alta meta sería la unificación e igualdad entre los nacientes Estados.

Paradójicamente, las ideas de una identidad nacional fueron insuficientes al reconocer como parte de este proceso a las poblaciones oprimidas, segregadas por las políticas coloniales impuestas por la razón ilustrada en América Latina. Ejemplo de esta ceguera son las poblaciones indígenas y

3 ¿Qué es la Ilustración? 
negras que continuaron siendo el reflejo de las agresiones imputadas al proyecto de la modernidad.

Es necesario decir que las normas del régimen colonial y el proyecto de modernidad europea en América Latina, no sólo configuraron las ideas de un proyecto identitario que buscaba albergar las expresiones sociales y culturales, también gestó el camino para instalar las bases de otra forma de colonialismo, esta vez, gestado en el interior de los territorios -antes sometidos al régimen colonial- la idea de un "colonialismo interno" ejercido por los criollos intelectuales, quienes revivían prístinos problemas, colocando nuevos debates en la escena política y cultural.

La noción de "colonialismo interno" sólo ha podido surgir a raíz del gran movimiento de independencia de las antiguas colonias. La experiencia de la independencia provoca regularmente la aparición de nuevas nociones, sobre la propia independencia y sobre el desarrollo. Con la independencia política lentamente aparece la noción de una independencia integral y de un neocolonialismo; con la creación del Estado-nación, como motor del desarrollo aparece en un primer plano la necesidad de técnicos y profesionales, de empresarios, de capitales. Con la desaparición directa del dominio de los nativos por el extranjero aparece la noción del dominio y la explotación de los nativos por los nativos (González Casanova, 2006, p. 186).

Las ideas de un "colonialismo interno" reforzaron una dudosa identidad nacional, manifestándose en la construcción de los primeros Museos Nacionales, y así afianzar aún más el proyecto de la modernidad/colonialidad. González Casanova argumenta que:

En la literatura política e histórica de los siglos XIX y XX se advierte cómo los países latinoamericanos van recogiendo estas nuevas experiencias, aunque no las llamen con los mismos nombres que hoy usamos. La literatura "indigenista" y liberal del siglo XIX señala la sustitución del dominio de los españoles por el de los "criollos", y el hecho de que la explotación de los indígenas sigue teniendo las mismas características que en la época anterior a la independencia (González Casanova, 2006, p. 186).

El nuevo posicionamiento social de la clase criolla e ilustrada Latinoamericana habilitó la creación de instituciones académicas, asociadas a ellas aparecen los espacios para los primeros museos. Así, por ejemplo, el Museo Nacional de Colombia abrió sus puertas al público en 1823, mientras que 
el Museo Nacional de Arqueología e Historia del Perú lo hizo un año antes, en 1822. La apertura de estas instituciones estuvo acompañada de símbolos que fomentaban los ideales de una clase social compuesta por notables ilustrados de la época.

En lo que atañe al primer museo referido, fue el Estado quien originalmente fomentó su creación, avivando los ideales de la prematura nación que buscaba fomentar el conocimiento científico en virtud del progreso, así:

El $1^{\circ}$ de mayo de 1822, Francisco Antonio Zea visitó en París al Barón Cuvier para solicitar su ayuda en la contratación de una comisión científica, con el fin de fundar "un establecimiento consagrado al estudio de la naturaleza, al adelanto de la agricultura, las artes y el comercio como fuentes de progreso". Con el mismo propósito entrevistó Zea al Barón Alexander von Humboldt y a Francisco Arago. De esta manera fueron designados Jean-Baptiste Boussingault para crear una división de química; François-Désiré Roulin, para actuar en fisiología y anatomía; Justin-Marie Goudot, en zoología y James Bourdon, como eslabón entre el futuro Museo Nacional y la Academia de Ciencias de París. (Rodríguez, 2008, pp. 8-9).

El museo destinado a la conservación y preservación de las expresiones materiales del pasado, hizo de ellas evidencias materiales con fines que pretendían la unificación nacional. Además, de acuerdo con las finalidades del progreso y perfeccionamiento humano, a saber: el estudio de la naturaleza, y el desarrollo tanto de las artes como del comercio y la agricultura, fue posible el establecimiento de políticas y normas restrictivas a las clases ya segregadas que negaron las realidades sociales y culturales que vivían las poblaciones, especialmente las poblaciones negras que durante un espacio de tiempo sumamente dilatado habían sido excluidas de una participación en proyectos culturales en Latinoamérica.

Puesto que el museo fue creado a expensas de una red universal, entendida en términos de la razón, contribuiría al proyecto de colonialidad $/ \mathrm{mo-}$ dernidad, afianzó aún más las dinámicas de poder en los sectores tanto de la academia como de la cultura en diversos países latinoamericanos, dichas dinámicas antes señaladas, más complejas que las de siglos anteriores. En términos generales, se puede decir que el colonialismo del poder se formuló en los siguientes presupuestos:

Consiste, en primer término, en una colonización del imaginario de los dominados. Es decir, actúa en la interioridad de ese imaginario [...] La repre- 
sión recayó ante todo sobre los modos de conocer, de producir conocimiento, de producir perspectivas, imágenes y sistemas de imágenes, símbolos y modos de significación; sobre los recursos, patrones e instrumentos de expresión formalizada y objetivada, intelectual o visual [...] Los colonizadores impusieron una imagen mistificada de sus propios patrones de producción de conocimientos y significaciones (Quijano, 1992, p. 438).

El colonialismo interno (González Casanova, 2006) y el colonialismo del poder (Quijano, 1992), continuaron retroalimentados por las propias dimensiones simbólicas inmanentes a los objetos expuestos en los museos, fortalecieron el orgullo en las clases criollas que creyeron haber superado el colonialismo europeo. Las condiciones sociales y culturales en las que se originó y desarrolló la institucionalidad del museo, propiciaron, no sólo el avance y exclusión social de algunas prácticas académicas, también originaron un escenario asimétrico y con profundas aristas que aún no se superan.

\section{III}

Las aristas políticas, sociales, económicas y culturales originadas en el seno del colonialismo, continuaron siendo motivadas en el período de la ilustración criolla, configurando campos del saber y así legitimar a la erudición, signo muy propio en este caso para configurar y excluir al "otro". Cayendo nuevamente en el atolladero, a saber, la posible reconstrucción del pasado, a partir de parámetros muy propios de la vida intelectual de Occidente, dejando sin la atención que se merecen los conocimientos, historias y saberes de los pueblos latinoamericanos.

La reconstrucción del pasado y su exposición en los museos indican claramente estrategias y técnicas de una memoria colectiva/ colonial, que son referencias para procesos de identidad y al mismo tiempo muestra esa paradoja antes señalada: la insuficiencia en la inclusión de aquellos sectores segregados, ya indiscriminados. Siendo el resultado de todo esto, configuraciones sociales tanto antagónicas como asimétricas en el contexto latinoamericano.

El museo, más allá de ser una institución que salvaguarda los vestigios del pasado, se ha erigido como una tecnología del saber ilustrado, cuyos desenlaces radican en la legitimización de hegemonías políticas e ideológicas contribuyentes a la retro alimentación del proyecto de la modernidad/ colonialidad en América Latina. 
De acuerdo con los parámetros estéticos exigidos por un arte europeo, se selecciona, imponen y se determinan los elementos que posiblemente se arroguen cierta fidelidad con el pasado, quedando una historia mutilada, mostrada como oficial, la cual es inexorable ciertamente con las historias paralelas al oficialismo. Dichos parámetros estéticos antes señalados, refuerzan la estructura del colonialismo, convirtiéndolo en la extensión privilegiada de la ideología dominante y a esto se añade una suerte de cultura profesada como bien económico y no en términos de derecho colectivo.

Por tanto, los objetos exhibidos en los museos son reglamentados por organismos de poder y clases dominantes vigentes, que pretenden continuar retro alimentación el sistema colonial de la modernidad, cuyo resultado inmediato es un conocimiento histórico amputado y una falta de flexibilidad con las distintas expresiones culturales, a las que se les ha imputado el nombre de "no oficiales".

Este hecho contrasta con la diversidad social y con los pensamientos constituyentes de las bases sociales e ideológicas en Latinoamérica; que establece espacios en los que las formas simbólicas del pasado adquieren dos matices: por un lado, la historia ideológica, hegemónica y dominante; y por otra parte, la historia excluida, colonial y subalterna del "otro".

Estas dos formas simbólicas de la historia evidencian un pasado latinoamericano de contrapoderes en el ámbito de la memoria social y colectiva (Graeber, 2004), guardando una estrecha relación con lo que argumenta el historiador Chakrabarty (2002, p. 12), cuando plantea la existencia de dos formas de historia en conflicto: la "historia 1", construida desde la perspectiva del capital, y la "historia 2" elaborada afuera de las formas y realidades asumidas por el capital.

La historia no solo se encarga de configurar un contrapoder que irremediablemente excluye y crea notables diferencias entre lo que se expone o no al interior del museo, también anula las razones simbólicas que tiene la "historia 2" para defender su pasado y resignificarlo en este espacio. Así, se plantea la necesidad de realizar un trabajo alterno a los impactos generados por las interpretaciones estructuradoras del proyecto de modernidad/colonialidad latinoamericano; se trata de un proyecto emancipatorio que garantice que las interpretaciones de la "historia 1" sean re-interpretadas desde ángulos no percibidos, y que las voces no escuchadas de los excluidos permitan la construcción del conocimiento sobre la historia social y colectiva latinoamericana. 
Este trabajo puede ser una aproximación valiosa en términos teóricos y metodológicos para avanzar en la comprensión de las realidades sociales, espaciales y temporales en las que se desarrollan iniciativas emergentes de la "historia 2"; sobre todo porque permitirían realizar inflexiones discursivas que situarían en el aquí y ahora a las historias subalternas, sus realidades políticas y económicas, y abrirían caminos para la construcción colectiva del conocimiento.

Se observa con frecuencia la escasez productiva de conocimientos colectivos que se pudiesen desarrollar en torno a la institución del museo, cayendo en el menoscabo y en la esterilidad de reflexiones sobre la historia y los caminos que esta ha tomado en nuestros contextos: principalmente porque la historia constituye un punto de disputa política y económica que en sus funciones: configura, legitima, y excluye a grandes sectores sociales.

\section{IV}

En los contextos latinoamericanos se hace indispensable pensar y debatir al interior de los museos la relevancia que podrían adquirir las miradas y concepciones subalternas del pasado, generando procesos interpretativos que deconstruyan las memorias de la modernidad/colonialidad. Al mismo tiempo es necesario analizar la responsabilidad de la investigación en estas construcciones, ya que a partir de ellas se afianzan ideas y referentes culturales que configuran elementos de la memoria social y colectiva, como mecanismos de reproducción colonial.

Los mecanismos ocultos de la colonización europea tras los museos son tal sutiles, que pasan inadvertidos a los ojos de los observadores; sin embargo, la posible generación de conocimientos en torno a las colecciones museísticas puede ser una herramienta de cambio y transformación de las sociedades latinoamericanas. Problematizar las concepciones estéticas con las que se origina y se reproduce el conocimiento en los museos puede ser un poderoso mecanismo para la decolonialidad de las miradas, que se encuentran reencarnadas en las formas y maneras en las que se venden los objetos en las exposiciones museísticas.

Deconstruir las miradas estéticas del proyecto museístico de modernidad/colonialidad implica acercarse a las sociedades, e indagar los ángulos poco percibidos y las voces no escuchadas en la construcción del conoci- 
miento. Esta deconstrucción constituye un punto de inflexión en el contexto latinoamericano, ya que posibilita discutir sobre las percepciones del pasado producidas por la academia, cargada de excesos y abusos colonialistas; la cual no reconoce la capacidad innata de las sociedades en la construcción y producción de saberes. Esta realidad plantea que la producción de conocimiento sobre el pasado está fuertemente anclada a una tradición en la que la noción de museo encarna y reproduce los patrones del colonialismo.

Barringer y Flynn (1998) plantean que la crítica poscolonial se centra en la condición de la representación implícita en los discursos y sus imágenes, pero ignoran la carga simbólica de la cultura material expuesta en los museos. En tal medida, el museo como institución requiere emprender procesos que desplacen y descentralicen la visión excluyente y colonial del proyecto de modernidad/colonialidad, incorporado en los objetos de cultura material.

Asimismo, dichos procesos pueden conducir a ulteriores reflexiones más amplias y profundas. Por ejemplo, debatir la influencia que ejerce occidente sobre el pensamiento social latinoamericano y las construcciones del pasado a partir de la cultura material; puesto que el museo retroalimenta los modelos del sistema colonial y los valores en los que se asienta, imposibilitando la generación de reflexiones tanto en el aprendizaje como en la producción del discurso.

La importancia que adquiera la reflexión social y académica al interior de los museos conducirá a un posible proceso decolonial, tanto de la mirada de los curadores como la del público visitante a los museos; a su vez se pueden propiciar debates sobre las imposiciones coloniales existentes sobre el pasado. Estas iniciativas proporcionarían insumos para reconocer la diversidad del pasado y las construcciones sociales que caracterizan los contextos latinoamericanos. En síntesis, resulta indispensable generar estos procesos para la construcción colectiva de los pasados, y ampliar las críticas a la fosilización del patrimonio.

Esta reflexión también advierte sobre un aspecto que es motivo de discusión actual, como es el déficit de estrategias educativas en los museos que pasan por alto la urgente necesidad de emprender procesos decoloniales del ser y el saber, como derecho de la sociedad por conocer y construir su pasado, y su memoria colectiva. Este fenómeno merece una crítica consistente con los procesos que se desarrollan al interior del museo, puesto que la educación ha sido empleada como tecnología de reproducción colonial, y con ello evidentemente: valores, configuraciones de occidente permanecerán vi- 
gentes en el seno de las sociedades latinoamericanas, imposibilitando rescatar su alta diversidad.

Por tal motivo planteo pensar la educación en el museo como una práctica liberadora que se sitúe en los propios contextos sociales; una educación que permita la identificación, el análisis y la comprensión de las estrategias coloniales, que busquen la reproducción de la historia y sus formas simbólicas ocultas en el discurso proyectado en los museos. La labor del museo y sus procesos educativos deben abolir la formación de subjetividades modernas y coloniales; y convertir sus salas de exposición en espacios para la reflexión crítica y el desmantelamiento del aparato colonial existente en su interior como institución.

\section{V}

Para concluir, se puede inferir del cúmulo de procesos y estructuras enfocadas a reconstruir el pasado, un carácter occidental que continúa afianzando percepciones y miradas académicas del proyecto de modernidad/colonialidad, y al mismo tiempo, se observa la anulación de cualquier tipo de posibilidades constructivas y reflexivas de los saberes autónomos. Esta penosa realidad demuestra que la producción de conocimiento social, al igual que los procesos educativos está anclada a tradiciones ortodoxas; es decir, este síntoma de ceguera tanto en el mirar como en el reconocer historias paralelas a las "oficiales", imposibilita espacios de pluralidad histórica y cultural que se debiesen solventar en el museo.

Las razones para permear esta realidad pueden ser diversas, identificando algunos factores: en primer lugar, la reproducción de concepciones y visiones del pasado que continúan afianzando modelos segregacionistas de las poblaciones, siendo ineficaces al tratar de brindar respuestas a las exigencias propias de las realidades Latinoamericanas. En segundo lugar, la reproducción del pensamiento moderno/colonial implica el sacrificio de la diversidad social, so pretexto de continuar nombrando el mundo con conceptos y paradigmas del siglo doce que continúan anquilosados en la academia Latinoamérica; y cuyos intelectuales y profesores reconstruyen -en la actualidad- la vida de los grupos humanos del pasado discriminatoriamente, haciendo parte esencial de los guiones estas visiones. 
En tercer lugar, no sólo se reproducen perspectivas mercantilistas con la gestión del pasado; sino también se ha tomado a la cultura material como un objeto comercial y de divertimiento burgués ofertado a los museos. En algunos casos, resulta casi imposible superar esta visión porque sus principales beneficiarios son los mismos intelectuales y conocedores del pasado, que ven en esta forma de gestión una manera de superar la derruida economía intelectual de la región.

En cuarto lugar, el pasado se redujo a simples factores económicos que van desde el turismo patrimonial, arqueológico, cultural y ecológico, hasta la creación de safaris fotográficos en ciudades de interés patrimonial. La gestión del pasado fosilizado como patrimonio e institucionalizado en el museo se convirtió en un cruce de intereses mercantilistas y particulares, dejando a un lado la importancia que poseen estos lugares como espacios de interpretación, interpelación y disertación del pasado; espacios que podrían configurarse como mecanismos para desmontar elementos del proyecto de modernidad/colonialidad y aportar a la construcción del presente y el futuro de las generaciones venideras.

Finalmente, es preciso llamar la atención sobre las formas mercantilistas de ver y vender el pasado en el contexto latinoamericano y la responsabilidad que tienen los museos frente a este tema, el cual podrá ser superado proponiendo reflexiones frente a la colonialidad de la memoria, la segregación y la racialización con la que se construye el pasado y su exhibición en los museos. En esencia se trata de una práctica deconstructiva, encaminada a la decolonialidad del pasado como mecanismo para la formulación de políticas públicas en las ciudades, y el fomento de iniciativas de multivocalidad e investigación participativa que conduzcan a la creación de museos incluyentes en la construcción de sus historias locales e incentivar conocimientos y disertaciones sobre el pasado.

\section{Bibliografía}

Barringer, T. y Flynn, T. (1998). Colonialism and the object. Empire, Material Culture and the Museum. Londres: Routledge.

Castro-Gómez, S. (2010). La hybris del punto cero. Ciencia, raza e Ilustración en la Nueva Granada (1750-1816). Bogotá: Pontificia Universidad Javeriana.

Césaire, A. (2006). Discurso sobre el colonialismo. En: Discurso sobre el colonialismo (pp. 13-43). Madrid: Akal. 
Chakrabarty, D. (2002). Universalism and Belonging in the Logic of Capital. En: Carol A. Breckenridge, Sheldon Pollock, Homi K. Bhabha, y Dipesh Chakrabarty (Eds.), Cosmopolitanism. Durham: Duke University Press.

González Casanova, P. (2006). El colonialismo interno. En: Pablo González Casanova, Sociología de la explotación. (pp. 185-205). Buenos Aires: CLACSO, Consejo Latinoamericano de Ciencias Sociales.

Graeber, D. (2004). Fragments of an anarchist anthropology. Chicago: Prickly Paradigm Press.

Hernández, F. (1992). Evolución del concepto de museo. Revista General de Información y Documentación, 2 (1), 85-97. Madrid: Editorial Complutense.

Quijano, A. (1992). Colonialidad del poder, cultura y conocimiento en América Latina. En: Santiago Castro-Gómez, Oscar Guardiola Rivera y Carmen Millán de Benavidez (Eds.), Pensar (en) los intersticios. Teoría y práctica de la crítica poscolonial (pp. 201-246). Bogotá: CEJA.

Pérez, A. (1977). Presente, pasado y futuro del Museo del Prado. Madrid.

Rodríguez, M. (2008). Aproximaciones a la historia del Museo Nacional. Origen de la institución museal en Colombia: entidad científica para el desarrollo y el progreso. En: Cuadernos de Curaduría. pp. 1-21. Edición especial. Recuperada http://www.banrepcultural.org/sites/default/files/rodriguez maria_paola_articulo.pdf [Consultado 01-05-2015] 